\title{
OPEN INNOVATION AS A FACILITATOR FOR CORPORATE EXPLORATION
}

\author{
BJÖRN REMNELAND WIKHAMN* and ALEXANDER STYHRE \\ School of Business, Economics and Law \\ University of Gothenburg, PO Box 610, SE-40530, Gothenburg, Sweden \\ *bjorn.wikhamn@handels.gu.se
}

Published 20 December 2016

\begin{abstract}
While open innovation is a management concept of increased attention in academia as well as in industry, studies have also shown that the implementation of open innovation can be a rather difficult and challenging process. Installed organisational structures, culture and knowledge are often portrayed as hinder for change. This study provides an in-depth case study, based on 50 interviews, of how a large pharmaceutical corporation implemented an open innovation initiative. Instead of considering existing internal knowledge and structures as problematic, these resources were rather utilised as cornerstones for value offerings in open innovation. Furthermore, employees' engagement in open innovation resulted in a more open and dynamic climate, as well as an improved entrepreneurial image of the corporation internally as well as externally. The study contributes to the open innovation literature by advancing the understanding about the organisational implications of implementing open innovation in practice. As such, it provides valuable insights for researchers and practitioners about implementing open innovation in practice.
\end{abstract}

Keywords: Open innovation; implementation; ambidexterity; exploration; organisational identity; life science.

\section{Introduction}

Corporations that are not adaptive and innovative face substantial risks of decline (Levinthal and March, 1993; Teece, 2007). Moreover, when organizations become older and bigger, their path-dependent decisions (Coombs and Hull, 1998) and

\footnotetext{
${ }^{*}$ Corresponding author.
}

This is an Open Access article published by World Scientific Publishing Company. It is distributed under the terms of the Creative Commons Attribution 4.0 (CC-BY) License. Further distribution of this work is permitted, provided the original work is properly cited. 
installed bases (Farrell and Saloner, 1985) of knowledge, technologies and processes lead to high switching costs in both core capabilities, materialised structures and established corporate culture. Hence, exploration of new possibilities tend to be crowded out by exploitation of old certainties over time (cf. Davis et al., 2009; March, 1991). Ways of avoiding this 'incumbent's curse' (Chandy and Tellis, 2000; Foster, 1986) have in recent past been in centre of attention for managers and business scholars. Open innovation (Chesbrough, 2003) is an increasingly popular concept for companies to explore new possibilities by opening up their boundaries for inflow and outflow of knowledge in order to accelerate value creation and build new paths for value capture. The literature on open innovation has grown exponentially in the last decade (Enkel et al., 2009; Randhawa et al., 2016; West and Bogers, 2014; West et al., 2014), but the challenge is that the concept is broad and rather vague (Dahlander and Gann, 2010) and can be utilised in many different ways, based on different logics (Remneland Wikhamn, 2013) and with different outcomes.

Although the open innovation community is growing and the research domain is maturing (Chesbrough and Bogers, 2014; West et al., 2014), more knowledge is needed on how to implement various forms of open innovation in practice and what consequences such initiatives have on the focal firm (Chesbrough et al., 2014). The few qualitative case studies of open innovation implementation reveal that it can be a rather difficult journey (Chiaroni et al., 2011). Problems of building absorptive capacity (Spithoven et al., 2010), dynamic capabilities (Chiaroni et al., 2010), transforming 'the not invented here-syndrome' (Chesbrough and Crowther, 2006) and creating an open work climate (Remneland Wikhamn and Wikhamn, 2011) have been pointed out as key difficulties. In this emerging research field, the potentials and challenges of implementing open innovation in practice need more attention. In this regard, in-depth investigations have been called for, especially with the link to the literature on management and organization (West et al., 2014).

In this paper, we analyse the implementation of an open innovation initiative called BioVentureHub in AstraZeneca, a large pharmaceutical corporation. Based on a longitudinal empirical study, the establishment of this open innovation initiative has been followed over three years. The pharmaceutical industry, and life science in general, face big challenges of managing innovation (Robbins and O'Gorman, 2015), due to extremely complex and uncertain development processes, with increased demands from key stakeholders (e.g., regulatory authorities, politicians, users, investors, media), long lead-times, large investments and huge financial risks, and high failure rates (Cowlrick et al., 2011; Gassmann and Reepmeyer, 2005). It is an industry that has been described as stalling (Gassmann and Reepmeyer, 2005; Hedner, 2012; Hunter and Stephens, 2010), especially for 
'Big Pharma' corporations (Munos, 2009). In light of these industrial challenges, open innovation is increasingly proposed as a way to strengthen the actors within the life science industry (Chesbrough and Chen, 2015; Hedner, 2012; Hessel, 2005; Hunter and Stephens, 2010; Munos, 2006; Munos and Chin, 2009).

The study contributes to the open innovation literature by advancing the understanding about the organisational implications of implementing open innovation in practice. A qualitative empirical study is provided on how corporate exploration is enhanced through open innovation within the life science industry. AZ BioVentureHub emerged as an innovative way of better utilising AstraZeneca's internal capacity of knowledge, resources and facilities to invite also external actors to colocate businesses on the AstraZeneca research site. Over time, the initiative turned into a driver for AstraZeneca as a whole to becoming more entrepreneurial. The open innovation initiative positively influenced AstraZeneca's explorative orientation by promoting entrepreneurial experiences and strengthening the entrepreneurial image, internally and externally. As such, the open innovation initiative did not only bring new monetary value streams and a further utilisation of resources, but it also facilitated an empowered work climate for the corporation's employees.

The reminder of the paper is organised as follows. First, an overview of the literature on open innovation and implementation is presented, followed by a method section. The case of the AZ BioVentureHub is then introduced and analysed, ending up in a discussion and concluding remarks.

\section{Implementing Open Innovation}

Open innovation has become a central topic within the broader innovation management field (Huizingh, 2011), adding an exponential number of academic contributions (Chesbrough and Bogers, 2014; Randhawa et al., 2016). However, it is still a relatively new field of research (West et al., 2014) with many emerging areas. One such underdeveloped topic is how to manage the implementation process of open innovation in practice (Vanhaverbeke et al., 2014; West et al., 2014). Some empirical studies have touched upon the implementation challenges of open innovation (e.g., Chiaroni et al., 2010, 2011; Di Minin et al., 2010; Mortara and Minshall, 2011), but more qualitative in-depth studies as well as quantitative survey-based studies are needed to explore the specific challenges and opportunities that meet practitioners when implementing open innovation initiatives. Especially, since open innovation is a very broad concept (Dahlander and Gann, 2010; Remneland Wikhamn, 2013) that is adopted in various contexts and contingencies (Van de Vrande et al., 2010). There are arguably vast differences between implementing, e.g., an innovation contest, an open innovation platform, 
an industry-university collaboration or an open business model. Certain open innovation activities may involve no implementation challenges at all since they are close to business-as-usual for the focal firm, while others may entail massive organisational transformations.

In the later domain, Remneland Wikhamn's (2011) study on Volvo Group argues that mature firms face a 'liability of oldness' when implementing open innovation due to historical path dependent decisions (David, 1988), manifested into internal structures, processes and culture. In other words, a transition toward open innovation requires high motives, endurance and strong top management support. Therefore, it is not strange that many open innovation cases have been initiated as a response to a severe crisis, as for instance visible in Di Minin et al. (2010) study on Fiat, and Huston and Sakkab (2006) account about Procter \& Gamble. Chiaroni et al. (2010) longitudinally studied four Italian mature firms' transition from closed to open from Lewin's (1951) three-stage model of change (unfreeze-change-refreeze). They suggest that the journey toward openness was facilitated by a change in organisational structure, which signalled to the stakeholders that the status quo had been unfrozen. Furthermore, they highlight the importance of open innovation champions with vast social networks, and the significance of identifying early pilot projects.

Both Chesbrough (2003) and von Hippel (2005) suggest that organisations that are overly protective of their knowledge may miss opportunities to engage in valuable knowledge exchange. However, this perspective does not suggest a binary classification between open vs. closed (Dahlander and Gann, 2010), but rather views it as a balancing act of openness and appropriability (Laursen and Salter, 2014) Henkel (2006) points out a process of 'selective revealing' in a study of firms' engagement in the open source development of Linux, i.e., firms are actively managing this tension between revealing and protecting in open innovation initiatives. When extending the innovation process to actors outside of the boundaries of the firm, it calls for new governance modes (Demil and Lecocq, 2006), but also new organisational values and an entrepreneurial climate that supports employees' difficult balancing between value creation and value appropriation.

The internal organisational culture has in the open innovation literature been portrayed as a prerequisite for change (Gassmann et al., 2010), but is also often seen as a hinder. Most commonly, Katz and Allen (1982) 'not-invented-heresyndrome' (NIH) has been highlighted as problematic for organisations that aim to open up for inflow and outflow of knowledge in innovation work [cf. Antons and Piller, 2015; Chesbrough, 2003; Dahlander and Gann, 2010; Gassmann, 2006; Hussinger and Wastyn, 2016). NIH is a profound attitude bias toward knowledge derived from external sources, irrespective of its objective value. Antons and Piller (2015) propose the need for appropriate instruments to measure the NIH in 
organisations, and Hussinger and Wastyn (2016) argue that NIH is stronger for knowledge arriving from external sources of similar characteristics as the in-group (i.e., direct competitors), and that NIH is more likely to occur within successful companies.

Organisational culture has also been pointed out as a facilitator for organizational ambidexterity (Gibson and Birkinshaw, 2004; Simsek, 2009), that is, the ability to simultaneously reconcile exploration and exploitation (March, 1991). Furthermore, Tellis (2006) is pointing out visionary leadership and an internal culture based on willingness-to-cannibalise as explanatory variables for a firm's ability to face disruptive market forces. In this regard, open innovation can be seen as a potential vehicle for incumbent firms to expand new explorative venues and to avoid the 'incumbent's curse'. Open innovation initiatives tend to challenge the firm's strategic comfort zone by introducing more distributed structures and processes. Implementing open innovation is therefore not only entangled with organisational culture, but arguably also with the broader concept of organisational identity, since organisational resources such as knowledge, value propositions, and relations are likely to be influenced by how organisational members define 'who we are' (Kogut and Zander, 1992). Albert and Whetten (1985) early conceptualised an influential definition of organisational identity as "central, distinctive and enduring characteristic of an organization", suggesting somewhat stability and durability over time. More recent perspectives rather emphasise the dynamic and precarious character of organisational identity (Gioia et al., 2013), as it is continuously negotiated through interactions with the context (Weick, 1995). Gioia et al. (2000) furthermore connect organisational identity with organisational image, that is, projected perceptions and impressions about the organisation held by insiders as well as outside audiences. Similarly, Hatch and Schultz (1997) argue that organisational identity, image and culture form circular processes of mutual interdependence, bridging internal and external symbolic context of the organisation. Put differently, when organisations open up their innovation processes, new negotiations and redefinitions emerge on both the self-interpretation of organisational members, as well as on the projected image held by outsiders.

\section{Method}

A single case study approach (Eisenhardt, 1989; Eisenhardt and Graebner, 2007; Flyvbjerg, 2006; Ragin and Becker, 1992) is employed for the empirical investigation about challenges and opportunities of implementing open innovation in practice. A limitation to the study design is the issue of external validity - a single case study is always bound to its specifics and contextual arrangements. 
However, case study research is a well credited method for generating new empirically valid insights in the early stages of theory building (Eisenhardt and Graebner, 2007), especially in topics of high complexity. In other words, although case studies do not allow for statistical generalisations, they still can provide analytical generalisations in transforming empirical data to theory, rather than to population (Flyvbjerg, 2006; Yin, 1994).

\section{Data collection}

The qualitative empirical data were derived from an explorative study conducted as part of a three-year longitudinal research project commencing in 2013, about open and distributed innovation processes in the Swedish life science industry. In total, 50 interviews have been conducted with 37 individuals working in different positions within the industry. The respondents can be divided into three groups. The first group includes representatives from AstraZeneca who have been actively involved with the establishment of the open innovation initiative (e.g., the CEO and the $\mathrm{COO}$ of $\mathrm{AZ}$ BioVentureHub). With these respondents, we conducted recurrent interviews from Fall 2013 to Spring 2016 (11 interviews). The second group includes representatives from the companies that have located their businesses in the hub (15 interviews with respondents from 10 different companies). The last group includes representatives from other actors within the wider life science industry, including science parks, hospitals, incubators, consultants, university scientists, funders, and research institutes (24 interviews).

In-depth interviews provide experiences and opinions, and generate thick empirical descriptions (cf. Dunbar et al., 2003) from practitioners working with open innovation within the life science industry in their daily work. Interview guides were developed with broad topics and thematic questions, still allowing flexibility in each specific interview session (Kvale and Brinkmann, 2006). The interviews were recorded, and either summarised, including quotes that were perceived as interesting, or fully transcribed (Poland, 2001). On two occasions, seminars were held with key respondents to discuss the empirical findings and to test the researchers' interpretations. The interview data was also triangulated with document studies, such as e-mails, internal strategy documents, presentations, web site content etc.

\section{Data analysis}

The text material was coded based on general coding practices of qualitative research (Clarke, 2005; Corbin and Strauss, 2014; Miles and Huberman, 1984). The analytical process followed three general steps — open coding, axial coding 
and selective coding - although these activities have proceeded in an iterative rather than linear process. Furthermore, the coding procedure has been done for the overall project but also more in detail for this specific paper. In the open coding, we marked text sections with tentative labels that emerged from the interview transcriptions. The labels were initially quite many and also overlapping each other, why they were arranged into wider empirical categories (e.g., collaboration, building processes, mobilization, funding, incentives, value creation, organisational culture, interesting work, new relationships, benefits, challenges, etc.). The transcribed text sections were hence structured into "second-order concepts" in order to analyse and explain the patterns of the first-order data (Van Maanen, 1979). The transcribed texts were also marked in terms of who they referred to (providing categories such as AZ top management, BioVentureHub, Hub companies, AZ experts, etc.), and specific events and activities were temporally ordered.

The categories were continuously challenged and modified as the axial coding (i.e. finding relations between the categories) evolved. The concepts were also simultaneously aligned to key dimensions and areas of open innovation (e.g., inflow vs. outflow, pecuniary vs. non-pecuniary, transactional vs. relational, internal vs. external, absorptive capacity, $\mathrm{NIH}$ ), and implementation (e.g., motivation, governance, activities, culture). Some overlaps between empirical and theoretical categories unsurprisingly emerged, as the boundaries between theory and practice often tend to blur (e.g., some theoretical concepts are used practitioners too).

The empirical and theoretical analysis led to the emergence of this paper's focus, as the "entrepreneurial activities" in the AZ BioVentureHub were connected to "exploration outcomes" for the corporation. These outcomes were moreover not only pecuniary and transactional value creation (as often emphasised in open innovation literature), but also involved aspects such as changes in organisational culture, employee motivation, employer branding etc. The selective coding for this paper, hence, rested on linking the overall category of "entrepreneurial activities" with the category of "exploration outcomes" for AstraZeneca, and for this paper more specifically to "entrepreneurial image" and "organisational identity" as subcategories of "exploration outcomes". These categories were then structured and emplotted into a cohesive story (Boje, 2001; Czarniawska, 2000), where the tensions between categories were exposed, and with the theoretical purpose of the paper in mind.

\section{The implementation of $\mathrm{AZ}$ BioVentureHub}

AstraZeneca is a British-Swedish pharmaceutical corporation with about 60,000 employees and operates in more than 100 countries. In recent years, AstraZeneca has initiated major corporate restructuring programs, with consolidation and 
downsizing of internal research, and outsourcing of various activities to external collaborators. This has led to staff layoffs and site closedowns. Within this context, the site management in AstraZeneca Mölndal started in 2013 to draft an initiative that later would be called AZ BioVentureHub. The Mölndal site is one of three strategic R\&D centres, together with Cambridge, UK and Gaithersburg, US. It is located outside of Gothenburg, Sweden, and has about 2,400 employees. The architect behind the AZ BioVentureHub was the AstraZeneca Business Development Director in Mölndal, and he was able to mobilise internal and external support for the idea.

The initiative is built on the concept that AstraZeneca opens up office- and lab space to carefully chosen small and middle-sized life science companies. The companies sign rental agreements on these facilities, but the contracts also give them an opportunity to access AstraZeneca's world-class know-how, as well as unused resources and equipment. The employees in the small "hub" firms receive keycards to the whole AstraZeneca site, with the same permissions as regular staff, including access to the restaurant, the gym and other corporate facilities.

An important argument for gaining internal top management support was costneutrality, meaning that the new initiative should not give AstraZeneca additional costs. For this purpose, AstraZeneca was able to generate external funding from VINNOVA (Sweden's innovation agency), the regional government and a private industry leader. At the same time, AstraZeneca agreed to provide their resources and knowledge without own profit margins. Furthermore, the contracts with the hub companies made clear that AstraZeneca did not have any further economical claims (e.g., right of first refusal, options etc.) on the hosted companies and their businesses. This arrangement laid the foundation for the establishment of $\mathrm{AZ}$ BioVentureHub, and provided resources to build infrastructure and processes for the integration of the hub firms with AstraZeneca expertise.

AZ BioVentureHub was launched in early 2014 and the Business Development Director was formally assigned as the CEO. The AZ BioVentureHub was located at the centre of the R\&D site, with refurbished offices and labs connected by shared corridors and meeting launches. Initially, three life science companies moved in, agreeing to be early adopters. They were followed by an increasing number of tenants and the requests for becoming part of the initiative quickly grew. Hub firms were selected based that AstraZeneca's knowledge and resources would be beneficial for their innovation journeys. It was also emphasised that the companies should have a sound long-term stability, i.e., a secured funding and engaged in promising research. Another highlighted aspect was that the companies could provide synergies to each other. The degree of maturity of the hub companies has been seen as an important parameter for a fruitful and constructive dialogue with AstraZeneca. The purpose has not primarily been to help the hub 
companies to create intellectual property - it is more about acting as a lever to enhance their already existing patents (and other intellectual properties) and to actively guide them in the later stages of drug development.

While the CEO continued his strategic mobilisation of attention and interest for the initiative, a Chief Operating Officer (COO) was in 2015 recruited to the AZ BioVentureHub from AstraZeneca. His main responsibilities lay in the continued development of the hub's processes and infrastructure and to having an ongoing interaction with the hub companies. Much operational activities were on the agenda, everything from putting up new signs, to securing internet connections and telephone lines, to making inventories of services that AstraZeneca could offer. Although the life science industry has traditionally been heavily based on patents and trade secrets, the emerging climate among the co-located hub companies was open and inclusive. Also, the interactions between AstraZeneca and the hub companies were quite informal, although a rather structured process for it had been established. More specifically, when companies need expert help they call the $\mathrm{COO}$ who acts as a contact person and gatekeeper, but also as a 'boundary spanner' in connecting them with the right experts within the large corporation. The meetings are then facilitated by the $\mathrm{COO}$ who makes sure that, e.g., any secret information are not unintentionally disclosed by either side, that the discussions are documented, and that the scheduled times are being kept.

In 2016, the AZ BioVentureHub had grown to 19 companies and one academic group - in total about 80 persons - and the ambition was to continue growing it in a steady rate. The companies varied in market focus as well as in development stages, and this diversity had been an increasingly important criterion for selection. The co-location of firms had resulted in several collaborative projects and shared activities between hub companies and AstraZeneca, as well as between the hub companies themselves. In this sense, AstraZeneca was able to transform their internal resources to a vibrant and growing open innovation initiative.

\section{The AZ BioVentureHub Initiative's Reception}

There were naturally many obstacles for implementing the AZ BioVentureHub in practice, since the initiative challenged AstraZeneca's processes, structures, culture and internal politics. One initial encounter was, for instance, to gain access to the AstraZeneca resources, since the AZ BioVentureHub was organised as a separate legal entity outside of the main corporation. The internal demands for these key resources are cyclic, in that there are periods of over-capacity but also periods of under-capacity. An interlinked challenge was that resources are spread 
in different parts of the corporation, where the organisational incentives are not always very high to share them with others - especially with external companies.

However, when the external companies moved into the hub and started to have daily interactions with the AstraZeneca staff, utilising resources and asking for advices, they felt much welcomed. In interviews with representatives from the hub companies, much positive words were said about the established environment, and how AstraZeneca had facilitated the process. Naturally there were some administrative and operational difficulties in the beginning when new structures and processes were not in place, but overall the implementation was perceived as well executed, both by AstraZeneca and the external companies. A respondent from one of the first companies that moved in exemplified it with this statement:

There are probably thousands of things that they could have done better or differently, but I really feel that they try their best, and we try to understand that AstraZeneca is not used to this. They try to make the best of the situations, and they have good intentions. (CEO, hub company XX, 2015-06-04)

Another example is when one company asked for permission to work in AstraZeneca's facilities for researching with animals, and this caused huge administrative and practical difficulties to manage for AstraZeneca.

We have heard from [the $\mathrm{COO}$ ] that [the manager for animal research at the Mölndal Site] has been marvelous in her engagement and commitment to make this work. This is extremely sensitive work, and it has generated much administrative and security issues. It takes time, but [AstraZeneca] is very supportive. (R\&D manager, hub company YY, 2015-09-17)

The involvement and engagement from AstraZeneca employees and their constructive approach to solving problems, challenges and practicalities that continuously emerged during the implementation were many times highlighted by the Chief Operating Officer for AZ BioVentureHub. For instance, he stated:

I am always proud of my colleagues' attitudes toward these hub companies. When we have information meetings and presentations, people think that it is very good that it is a hub here, and ask how they might help or come into contact with the companies. It is certainly not something that "the cat has dragged in". And this makes my work much easier. (COO, AZ BioVentureHub, 2016-04-01)

There are several different explanations for why the AstraZeneca staff showed positive attitudes toward the AZ BioVentureHub already from the beginning. One 
precondition was the personal drive that the new CEO of the hub embraced, and the internal legitimacy that was generated from top management support. Another reason can be found in the existing local corporate culture, supporting curiosity, science and collaboration. An implicit drive could also be that the staff viewed the hub as a way to avoid further downsizing. One AstraZeneca manager (interview, 2015-10-07) stated, "It sounds altruistic, but here people really work for the company and doing what they believe is best for it. This culture is very strong".

Reasons for the internal positive reception of the AZ BioVentureHub were also based on a more personal level, such as the possibilities of gaining new knowledge and meeting new people. The engaged experts thought it was great fun, as this exposed them to new challenges and learning possibilities. They are themselves often tied up in long-term projects with much responsibilities and high risks. In these meetings, they sit down for an hour, looking into a fresh new project, without further commitments. They feel like specially picked experts, and they grow as individuals when sharing their knowledge. One manager put it like this:

Then there is also a personal interest in getting involved with the hub companies - everybody wants to nurture their external contacts, as you never know what lies ahead. And there is personal development factor. You are invited to see a new project, new challenges - you make a visit to a new world - and that is thrilling. (AstraZeneca manager, 2015-10-07)

The interactions with the hub companies also gave the involved AstraZeneca experts more direct positive feedback, recognition and acknowledgement as the hub companies showed gratitude of their knowledge and expertise.

We had a person who helped a company with a very concrete question. He came back and said to us, "this is something I do every day, but I have never got so much appreciation for it as I got today". (CEO, AZ BioVentureHub, 2014-09-04)

\section{The AZ BioVentureHub as a Mode of Exploration}

The implementation of the AZ BioVentureHub resulted in an increased mode of exploration within the AstraZeneca Mölndal R\&D centre. It supported the strategic journey that AstraZeneca communicated in 2013 with the three key areas: (1) achieve scientific leadership, (2) return to growth and (3) be a great place to work. The two first areas - knowledge and growth - have natural connections to the function of the hub, inviting external companies to bring in new perspectives and 
together transforming internal corporate capacities into new value propositions. A more or less unintended consequence was that the initiative also actively facilitated the movement of the third strategic area in AstraZeneca's strategy — to be a great place to work.

The AZ BioVentureHub initiative helped to translate AstraZeneca's strategic goals from mission- and policy documents into materialised practice. This was facilitated by two reinforcing elements: (1) enhanced entrepreneurial experiences, and (2) enhanced entrepreneurial image. Both domains worked together in building a more explorative workforce in AstraZeneca, and simultaneously facilitating the attraction, retention and development of the competences and resources of the firm.

I think AstraZeneca is doing this [AZ BioVentureHub initiative] to learn from the small firms. We have a different openness and more flexibility. We can inspire them to become more entrepreneurial. (R\&D manager, hub company YY, 2015-09-17)

This quote is pointing out one great benefit that the AZ BioVentureHub gave AstraZeneca in the short run. When integrating with the hub, the AstraZeneca staff clearly became inspired by new perspectives from the smaller and more agile hub companies. The AstraZeneca staff that was actively involved with the AZ BioVentureHub as experts for the hosted companies got opportunities not only to see new knowledge perspectives but also to gain concrete entrepreneurial experiences themselves when interacting with the companies.

They are experts in certain areas and when they sit down and discuss with the small company, they understand that one can see things differently and work in different ways. The small company works in a different way than the big company does, good or bad. (CEO, AZ BioVentureHub, 2015-05-25)

The involvement in the AZ BioVentureHub forced the staff from the big corporation to put themselves in the shoes of the entrepreneurs and small business managers with limited capital, resources, and time. Viewing the world from the entrepreneur's perspective challenged the internalised know-how and thus facilitated own creativity and reflection. The COO, who often participates in the scheduled meetings between AstraZeneca employees and the hub companies, noticed the following:

Our staff has become more extroverts, and can put themselves in the heads of the people in the hub companies. They do not say to [the hub companies] "we always do this, and you should also do 
so". They rather say "we use to do this way, but if I were you, I would have taken these shortcuts, but in these areas I would never compromise". (COO, AZ BioVentureHub, 2015-05-25)

The AZ BioVentureHub also generated more long-term possibilities for employees to integrate with the hub companies. Shared projects were initiated, and AstraZeneca also let some of their employees work part-time in the hub companies in order to learn a specific new technology or process. Certainly, this increased the risk of losing key personnel - either that they would move to other companies or starting their own businesses. But as one AstraZeneca manager explained: "We have become less protectionistic when it comes to competence. We cannot tie you to our company. If you really would like to leave, then nobody will be happy if you stayed".

Initiatives such as the AZ BioVentureHub are concrete actions that signal a new strategic course for the internal organisation. It somewhat shifted the attention from a cost-saving mode to a growth mode. Fear of downsising, competition and restructuring was substituted by enthusiasm, collaboration and creativity. In AstraZeneca, there was from the beginning a strong management support for the implementation of the hub. Partly, this was grounded in a belief that AstraZeneca needed to change its ways of innovating, but also to change how to look at their human resources in general. In order to attract and keep talents, the company constantly needs to provide inspiring possibilities and challenging work content.

The image of this place... [...] that it is not a strange facility out in the suburbs, but a dynamic and creative place. When aiming to attract international talents, then we can show that "here is something boiling". But this is soft. Very soft. It does not give us money in direct sense. But it provides our employees with new opportunities, and a new view of the company. (COO, AZ BioVentureHub, 2015-05-25)

Furthermore, the management support was also reinforced by the received PR value in relation to external stakeholders such as politicians, competitors, potential employees and collaborators. As the initiatives were described in positive terms by actors in the industry and in media, this aspect became increasingly important. The mobilisation of the hub led to more and more allies joining in - funders, partners and hub companies. Visits came from domestic as well as foreign ministers, policy makers and industry representatives - and they came specifically to see the AZ BioVentureHub. The CEO of the hub was invited as speaker on conferences, seminars and presentations. Also, other functions, such as HR, used the AZ BioVentureHub when describing AstraZeneca as a great place to work. The COO 
(2016-04-01) summarized it as; "Before, people believed that AstraZeneca was shutting down in Sweden, and that we are company that slowly is falling asleep. Now it is a completely different view - AstraZeneca is on the move".

To summarize, the establishment of the AZ BioVentureHub showed creativity and boldness and was also often communicated as a successful case, internally as well as externally. This facilitated an increased exploration mode in AstraZeneca and enriched the entrepreneurial climate. The AZ BioVentureHub enhanced entrepreneurial experiences and simultaneously made the entrepreneurial image of the corporation stronger - which in turn increased the likelihood of further entrepreneurial activities and experiences. Positive feedback-loops had started to develop - making the company more explorative as well as providing a greater place to work.

\section{Concluding Remarks}

Previous research on open innovation has raised incumbent firms' path dependency (Remneland Wikhamn, 2011), difficulties of transforming internal structures (Huston and Sakkab, 2006) and cultures (Gassmann et al., 2010), facing 'notinvented-here syndromes' (Katz and Allen, 1982), as well as a lack of absorptive capacity (Spithoven et al., 2010). Academic literature has described long and tough transformational processes (e.g., Chiaroni et al., 2010, 2011; Di Minin et al., 2010; Mortara and Minshall, 2011), where organisations need strong motives and top management support to embark such a journey (Di Minin et al., 2010; Huston and Sakkab, 2006). In the case of AZ BioVentureHub, no immediate crisis initiated the open innovation initiative, although a general corporate awareness existed about certain innovation challenges. The implementation was designed and carried out by a senior manager with a strong position within the corporation and with unconditional backup from the top management team. This is in line with the findings of Chiaroni et al. (2010), suggesting the need for open innovation champions with internal legitimacy in order to mobilising support for the change. These authors further highlight the importance of signalling the unfreezing of status quo toward important stakeholders, and also to start with smaller pilot projects to quickly concretise the ambitions. The AZ BioVentureHub was created as a separate legal entity, but was much integrated in the facilities and several of the organisational processes of the hosting firm. However, although AZ BioVentureHub was neither small, nor a pilot, it acted as a structural unfreezing signal to AstraZeneca as a way to exemplify and materialise the strategic intent through concrete actions. 
When implementing AZ BioVentureHub, the internal resources and processes of AstraZeneca were not considered as a 'liability of oldness' (Remneland Wikhamn, 2011) and belonging to 'the incumbent's curse' (Chandy and Tellis, 2000; Foster, 1986). On the contrary, the knowledge and resources were cornerstones for the value offerings to the hub companies. Nor was the existing corporate culture seen as a hinder are for implementing the AZ BioVentureHub, and the 'not-invented-here syndrome' (Katz and Allen, 1982) was quite easily held at bay. AstraZeneca was instead able to commute the open innovation initiative as something positive both for AstraZeneca and for the staff's own learning and work possibilities. As a result, when the corporation engaged in open innovation in practice, it helped adding to and transforming the understanding of how to translate their unique resources and competences into new constructive domains. Hence, the AZ BioVentureHub acted as a vehicle for an increased explorative orientation for the corporation and its staff - in other words, as a facilitator for organisational ambidexterity (Gibson and Birkinshaw, 2004; Simsek, 2009).

The vast literature on open innovation links "openness" to value creation and subsequently "closeness" to missed value opportunities (e.g., Chesbrough, 2003; von Hippel, 2005) and this empirical study shows that such value generation is exceeding pecuniary value. In fact, in the short term, economic growth and transactional value extraction were the least important outcomes of the AZ BioVentureHub. What was more evident was how the employees' engagement in open innovation resulted in a more open and dynamic climate - a better place for the employees to develop their skills and relationships. The openness linked to the establishment of AZ BioVentureHub also positively influenced the organisational image and identity (Gioia et al., 2000) for AstraZeneca, internally and externally.

This paper contributes to the academic field of open innovation by adding a study of open innovation implementation within the life science industry. In this industry, the concept of open innovation has been suggested as a promising mode for improving the innovation rate (Gassmann and Reepmeyer, 2005; Hedner, 2012; Hunter and Stephens, 2010). Hence, the study contributes to the open innovation field by complementing the vast empirical research on high-tech and consumer goods corporations with an in-depth study from an industry with different institutional preconditions. Within this setting, the AZ BioVentureHub is an innovative example of open innovation, and can act as a novel example for analysing implementation challenges in practice. This paper builds on a single case study of how AstraZeneca initiated and implemented an open innovation initiative named AZ BioVentureHub. In particular, we analyse and discuss the implications of such open innovation implementation on the ground, and over time. As such, it links open innovation to the broader field of management and organisation. The study connects open innovation to the domains of ambidexterity (Gibson and 
Birkinshaw, 2004; Simsek, 2009), as well as to organisational image and identity (Gioia et al., 2013, 2000; Hatch and Schultz, 1997; Kogut and Zander, 1992), expanding these research fields to include a case where organising takes place across the focal firm's organisational boundaries. The implementation of the open innovation initiative became a facilitator and a concrete and visible action to support the materialisation of the new strategy, including aspects of improving the entrepreneurial growth, providing the employees a great place to work, and indirectly promoting a stronger entrepreneurial culture, image and identity in a circular and reinforcing way.

The paper contributes to management practitioners by providing an in-depth case study of the implementation of open innovation in practice. Open innovation is a broad field, and arguably there are contextual as well as company differences, which make normative conclusions problematic. But case studies can provide inspirations for new, creative open innovation initiatives. The study of AZ BioVentureHub also nuances the difficulties and challenges of such implementation, lifting up evidences of positive, and from the outset unintended and unexpected, outcomes.

\section{References}

Albert, S and DA Whetten (1985). Organizational identity. In Research in Organizational Behavior, LL Cummings and BM Staw (Eds.), pp. 263-295. Greenwich, CT: JAI Press.

Antons, D and FT Piller (2015). Opening the black box of "Not Invented Here": Attitudes, decision biases, and behavioral consequences. The Academy of Management Perspectives, 29(2), 193-217.

Boje, DM (2001). Narrative Methods for Organizational and Communication Research. London: Sage.

Chandy, RK and GJ Tellis (2000). The Incumbent's Curse? incumbency, size, and radical product innovation. The Journal of Marketing, 64(3), 1-17.

Chesbrough, H (2003). Open Innovation: The New Imperative for Creating and Profiting from Technology. Boston, Mass.: Harvard Business School Press.

Chesbrough, H and M Bogers (2014). Explicating open innovation: Clarifying an emerging paradigm for understanding innovation. In New Frontiers in Open Innovation, H Chesbrough, W Vanhaverbeke and J West (Eds.), pp. 3-28. Oxford: Oxford University Press.

Chesbrough, H and EL Chen (2015). Using inside-out open innovation to recover abandoned pharmaceutical compounds. Journal of Innovation Management, 3(2), 21-32.

Chesbrough, $\mathrm{H}$ and A Crowther (2006). Beyond high tech: Early adopters of open innovation in other industries. $R \& D$ Management, 36(3), 229-236. 
Chesbrough, H, W Vanhaverbeke and J West (2014). New frontiers in open innovation. Oxford: Oxford University Press.

Chiaroni, D, V Chiesa and F Frattini (2010). Unravelling the process from closed to open innovation: Evidence from mature, asset-intensive industries. $R \& D$ Management, 40(3), 222-245.

Chiaroni, D, V Chiesa and F Frattini (2011). The open innovation journey: How firms dynamically implement the emerging innovation management paradigm. Technovation, 31(1), 34-43.

Clarke, A (2005). Situational analysis: Grounded theory after the postmodern turn. London, Thousand Oaks \& New Delhi: Sage.

Coombs, R and R Hull (1998). Knowledge management practices and path-dependency in innovation. Research Policy, 27(3), 239-256.

Corbin, J and A Strauss (2014). Basics of qualitative research: Techniques and procedures for developing grounded theory. Thousand Oaks, CA: Sage Publications.

Cowlrick, I, T Hedner, R Wolf, M Olausson and M Klofsten (2011). Decision-making in the pharmaceutical industry: Analysis of entrepreneurial risk and attitude using uncertain information. $R \& D$ Management, 41(4), 321-336.

Czarniawska, B (2000). The Uses of narrative in organization research. In GRI-rapport, 2000:5. Göteborg: Gothenbwg Research Institute.

Dahlander, L and D Gann (2010). How open is innovation? Research Policy, 39(6), 699-709.

David, PA (1988). Path-dependence: Putting the past into the future of economics. Institute for Mathematical Studies in the Social Sciences technical report No. 533, Stanford University.

Davis, JP, KM Eisenhardt and CB Bingham (2009). Optimal structure, market dynamism, and the strategy of simple rules. Administrative Science Quarterly, 54(3), 413-452.

Demil, B and X Lecocq, (2006). Neither market nor hierarchy nor network: the emergence of bazaar governance. Organization Studies, 27(10), 1447-1466.

Di Minin, A, F Frattini and A Piccaluga (2010). Fiat: Open innovation in a downturn (1993-2003). California Management Review, 52(3), 132-159.

Dunbar, C, D Rodriguez and L Parker (2003). Race, Subjectivity, and the interview process. In Inside Interviewing - New Lenses, New Concerns, JA Holstein and JF Gubrium (Eds.), pp. 131-150London, Thousand Oaks \& New Dehli: Sage.

Eisenhardt, K (1989). Building theory from case study research. Academy of management Review, 14(4), 532-550.

Eisenhardt, K and M Graebner (2007). Theory building from cases: Opportunities and challenges. Academy of Management Journal, 50(1), 25-32.

Enkel, E, O Gassmann and N Chesbrough (2009). Open R\&D and open innovation: Exploring the phenomenon. R\&D Management, 39(4), 311-316.

Farrell, J and G Saloner (1985). Standardization, compatibility, and innovation. Rand Journal of Economics, 16(1), 70-83.

Flyvbjerg, B (2006). Five misunderstandings about case-study research. Qualitative inquiry, 12(2), 219-245. 
Foster, RN (1986). Innovation: The attacker's advantage. New York: McKinsey.

Gassmann, O (2006). Opening up the innovation process: Towards and agenda. $R \& D$ Management, 35(3), 223-228.

Gassmann, O, E Enkel and M Chesbrough (2010). The future of open innovation. $R \& D$ Management, 40(3), 213-221.

Gassmann, O and G Reepmeyer (2005). Organizing pharmaceutical innovation: From science-based knowledge creators to drug-oriented knowledge brokers. Creativity and Innovation Management, 14(3), 233-245.

Gibson, CB and J Birkinshaw (2004). The Antecedents, consequences, and mediating role of organizational ambidexterity. The Academy of Management Journal, 47(2), 209-226.

Gioia, DA, SD Patvardhan, AL Hamilton and KG Corley (2013). Organizational identity formation and change. The Academy of Management Annals, 7(1), 123-193.

Gioia, DA, M Schultz and KG Corley (2000). Organizational identity, image, and adaptive instability. Academy of management Review, 25(1), 63-81.

Hatch, MJ and M Schultz (1997). Relations between organizational culture, identity and image. European Journal of marketing, 31(5/6), 356-365.

Hedner, T (2012). Change in the pharmaceutical industry: Aspects on innovation, entrepreneurship, openness, and decision making. Department of Management and Engineering. Linköping: Linköping University.

Henkel, J (2006). Selective revealing in open innovation processes: The case of embedded Linux. Research Policy, 35(7), 953-969.

Hessel, A (2005). Open source biology. In Open Sources 2.0, C DiBona, M Stone and D Cooper (Eds.), pp. 281-296Beijing: O'Reilly.

Huizingh, E. (2011). Open innovation: State of the art and future perspectives. Technovation, 31(1), 2-9.

Hunter, J and S Stephens (2010). Is open innovation the way forward for big pharma? Nature Reviews Drug Discovery, 9(2), 87-88.

Hussinger, K and A Wastyn (2016). In search for the not-invented-here syndrome: the role of knowledge sources and firm success. R\&D Management, 46(S3), 945-957.

Huston, L and N Sakkab (2006). Connect and develop: Inside procter \& gamble's new model for innovation. Harvard Business Review, 84(3), 58-66.

Katz, R and TJ Allen (1982). Investigating the Not Invented Here (NIH) syndrome: A look at the performance, tenure, and communication patterns. $R \& D$ Management, 12(1), $7-19$.

Kogut, B and U Zander (1992). Knowledge of the firm, combinative capabilities, and the replication of technology. Organization science, 3(3), 383-397.

Kvale, S and S Brinkmann (2006). InterViews - Learning the Craft of Qualitative Research Interviewing. Thousand Oaks: Sage.

Laursen, K and AJ Salter (2014). The paradox of openness: Appropriability, external search and collaboration. Research Policy, 43(5), 867-878.

Lewin, K (1951). Field Theory in Social Science. New York: Harper \& Row. 
Levinthal, DA and JG March (1993). The myopia of learning. Strategic Management Journal, 14, 95-112.

March, JG (1991). Exploration and exploitation in organizational learning. Organization science, 2(1), 71-97.

Miles, MB and AM Huberman (1984). Qualitative Data Analysis: A Sourcebook of New Methods. Beverly Hills, California: Sage Publications.

Mortara, L and T Minshall (2011). How do large multinational companies implement open innovation? Technovation, 31(10-11), 586-597.

Munos, B (2006). Can open-source R\&D reinvigorate drug research? Nature Reviews Drug Discovery, 5(9), 723-729.

Munos, B (2009). Lessons from 60 years of pharmaceutical innovation. Nature Reviews Drug Discovery, 8(12), 959-968.

Munos, BH and WW Chin (2009). A call for sharing: adapting pharmaceutical research to new realities. Science Translational Medicine, 1(9), 1-4.

Poland, BD (2001). Transcription quality. In Handbook of Interview Research: Context and Method, JF Gubrium and JA Holstein (Eds.), pp. 629-651. London: Sage.

Ragin, CC and HS Becker (1992). What is a case? Exploring the foundations of social inquiry. Cambridge: Cambridge university press.

Randhawa, K, R Wilden and J Hohberger (2016). A bibliometric review of open innovation: Setting a research agenda. Journal of Product Innovation Management, 33(6), 750-772.

Remneland Wikhamn, B (2011). Path dependence as a barrier for 'soft' and 'open' innovation. International Journal of Business Innovation and Research, 5(6), 714-730.

Remneland Wikhamn, B (2013). Two different perspectives on open innovation - Libre versus control. Creativity and Innovation Management, 22(4), 375-389.

Remneland Wikhamn, B and W Wikhamn (2011). Open innovation climate measure: The introduction of a validated scale. Creativity and Innovation Management, 20(4), 284-295.

Robbins, P and C O'Gorman (2015). Innovating the innovation process: An organisational experiment in global pharma pursuing radical innovation. $R \& D$ Management, 45(1), 76-93.

Simsek, Z (2009). Organizational ambidexterity: Towards a multilevel understanding. Journal of Management Studies, 46, 597-624.

Spithoven, A, B Clarysse and M Knockaert (2010). Building absorptive capacity to organise inbound open innovation in traditional industries. Technovation, 30(2), $130-141$.

Teece, DJ (2007). Explicating dynamic capabilities: The nature and microfoundations of (sustainable) enterprise performance. Strategic Management Journal, 28(13), 1319-1350.

Tellis, GJ (2006). Disruptive technology or visionary leadership. Journal of Product Innovation Management, 23(1), 34-38. 
Van de Vrande, V, W Vanhaverbeke and O Gassmann (2010). Broadening the scope of open innovation: Past research, current state and future directions. International Journal of Technology Management, 52(3/4), 221-235.

Van Maanen, J (1979). The fact of fiction in organizational ethnography. Administrative Science Quarterly, 24(4), 539-550.

Vanhaverbeke, W, H Chesbrough and J West (2014). Surfing the new wave of open innovation research. In New Frontiers in Open Innovation pp. 281-294 Oxford: Oxford University Press.

Weick, KE (1995). Sensemaking in Organizations. Thousand Oaks: Sage Publications.

West, J and M Bogers (2014). Leveraging external sources of innovation: A review of research on open innovation. Journal of Product Innovation Management, 31(4), 814-831.

West, J, A Salter, W Vanhaverbeke and H Chesbrough (2014). Open innovation: The next decade. Research Policy, 43(5), 805-811.

von Hippel, E (2005). Democratizing Innovation. Cambridge, Mass.: MIT Press.

Yin, R (1994). Case Study Research: Design and Methods. Thousand Oaks, CA: Sage Publications. 